\title{
Breastfeeding and infant eczema in the first year of life in the KOALA birth cohort study: a risk period-specific analysis
}

Citation for published version (APA):

Snijders, B. E., Thijs, C., Kummeling, I., Penders, J., \& van den Brandt, P. A. (2007). Breastfeeding and infant eczema in the first year of life in the KOALA birth cohort study: a risk period-specific analysis. Pediatrics, 119(1), e137-141. https://doi.org/10.1542/peds.2006-0772

Document status and date:

Published: 01/01/2007

DOI:

10.1542/peds.2006-0772

Document Version:

Publisher's PDF, also known as Version of record

Please check the document version of this publication:

- A submitted manuscript is the version of the article upon submission and before peer-review. There can be important differences between the submitted version and the official published version of record.

People interested in the research are advised to contact the author for the final version of the publication, or visit the DOI to the publisher's website.

- The final author version and the galley proof are versions of the publication after peer review.

- The final published version features the final layout of the paper including the volume, issue and page numbers.

Link to publication

\footnotetext{
General rights rights.

- You may freely distribute the URL identifying the publication in the public portal. please follow below link for the End User Agreement:

www.umlib.nl/taverne-license

Take down policy

If you believe that this document breaches copyright please contact us at:

repository@maastrichtuniversity.nl

providing details and we will investigate your claim.
}

Copyright and moral rights for the publications made accessible in the public portal are retained by the authors and/or other copyright owners and it is a condition of accessing publications that users recognise and abide by the legal requirements associated with these

- Users may download and print one copy of any publication from the public portal for the purpose of private study or research.

- You may not further distribute the material or use it for any profit-making activity or commercial gain

If the publication is distributed under the terms of Article 25fa of the Dutch Copyright Act, indicated by the "Taverne" license above, 


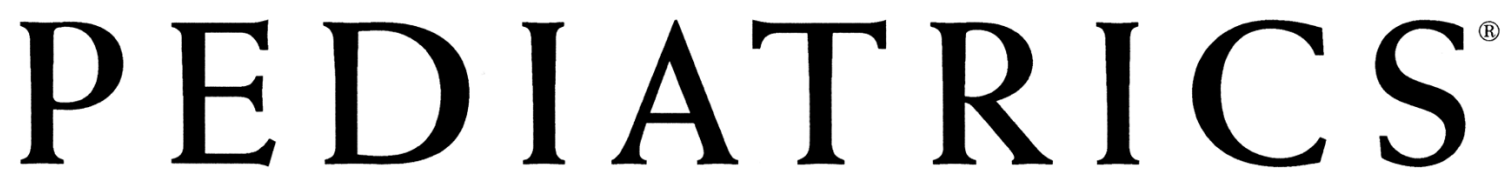

OFFICIAL JOURNAL OF THE AMERICAN ACADEMY OF PEDIATRICS

\section{Breastfeeding and Infant Eczema in the First Year of Life in the KOALA Birth Cohort Study: A Risk Period-Specific Analysis}

Bianca E. P. Snijders, Carel Thijs, Ischa Kummeling, John Penders and Piet A. van den Brandt

Pediatrics 2007;119; e137-e141

DOI: $10.1542 /$ peds.2006-0772

The online version of this article, along with updated information and services, is located on the World Wide Web at:

http://www.pediatrics.org/cgi/content/full/119/1/e137

PEDIATRICS is the official journal of the American Academy of Pediatrics. A monthly publication, it has been published continuously since 1948. PEDIATRICS is owned, published, and trademarked by the American Academy of Pediatrics, 141 Northwest Point Boulevard, Elk Grove Village, Illinois, 60007. Copyright @ 2007 by the American Academy of Pediatrics. All rights reserved. Print ISSN: 0031-4005. Online ISSN: 1098-4275.

\section{American Academy of Pediatrics}




\title{
Breastfeeding and Infant Eczema in the First Year of Life in the KOALA Birth Cohort Study: A Risk Period-Specific Analysis
}

\author{
Bianca E. P. Snijders, MSca, Carel Thijs, MD, PhD ${ }^{a, b}$, Ischa Kummeling, MSca, John Penders, MSc ${ }^{b}$, Piet A. van den Brandt, PhDa,b \\ aCare and Public Health Research Institute and bNutrition and Toxicology Research Institute Maastricht, Department of Epidemiology, Maastricht University, Maastricht, \\ Netherlands
}

The authors have indicated they have no financial relationships relevant to this article to disclose.

\section{ABSTRACT}

OBJECTIVE. We studied the association between breastfeeding and eczema, taking into account the possible influence of reverse causation, with risk period-specific analyses.

METHODS. Information on breastfeeding, determinants, and outcomes at 1 year of age was collected with repeated questionnaires for 2405 mother-infant pairs participating in the KOALA (Child, Parent and Health: Lifestyle and Genetic Constitution [in Dutch]) birth cohort study. By using multivariate logistic regression analysis, we compared an overall analysis with risk period-specific analyses.

RESULTS. By the age of 1 year, 535 infants $(22.2 \%)$ had developed eczema. In an overall analysis, we found a weak nonsignificant trend toward a reduced risk of eczema in the first year of life with increasing duration of breastfeeding (lowest risk for those breastfed for $\geq 7$ months versus never breastfed). In the risk periodspecific analysis (confined to infants "at risk" for eczema onset after 3 months of age), no indication for reverse causation was found (results were not very different, compared with the overall analysis). Infants who were breastfed from birth on had a slightly (although not statistically significantly) increased risk for eczema in the first 3 months of life, compared with infants who were formula fed from birth on.

www.pediatrics.org/cgi/doi/10.1542/ peds.2006-0772

doi:10.1542/peds.2006-0772

Key Words

eczema, breastfeeding, infant, cohort, epidemiology, bias, reverse causation

\section{Abbreviations}

KOALA—Child, Parent and Health: Lifestyle and Genetic Constitution (in Dutch)

OR - odds ratio

$\mathrm{Cl}$ - confidence interval

PPGP_-pregnancy-related pelvic girdle

pain

Accepted for publication Aug 2, 2006

Address correspondence to Bianca E.P.

Snijders, MSc, Department of Epidemiology, Maastricht University, PO Box 616, 6200 MD,

Maastricht, Netherlands. E-mail: bep.snijders@ epid.unimaas.nl

PEDIATRICS (ISSN Numbers: Print, 0031-4005; Online, 1098-4275). Copyright $\odot 2007$ by the American Academy of Pediatrics

CONCLUSIONS. Our results indicated that no strong effect of breastfeeding on eczema in the first year of life was present. This conclusion was strengthened by risk period-specific analysis, which made the influence of reverse causation unlikely. 
$\mathrm{T}$ O DATE, THE results of studies addressing the effect of breastfeeding on the development of allergic diseases have been controversial. ${ }^{1,2}$ Discussion of this topic revived after several studies reported that breastfeeding seemed to be a risk factor, instead of a protective factor, in the development of allergic diseases. ${ }^{3-6}$ Criteria for improved study design were proposed by Kramer ${ }^{1}$ in 1988, in an attempt to resolve the inconsistencies. Several studies focused on other methodologic explanations for the inconsistent results. ${ }^{7-10}$

Bias may occur as a result of disease-related modification of exposure, a concept introduced by Kull et $\mathrm{al}^{7}$ and also known as reverse causation ${ }^{8}$ or protopathic bias $^{11}$ in the literature. It is widely known that prolonged breastfeeding has many health benefits for the child. It is possible that mothers extend their breastfeeding if their child has suspected symptoms of eczema. ${ }^{4}$ However, mothers may cease breastfeeding because the child has persistence of allergic symptoms as a result of sensitization to dietary antigens of the mother's diet that are present in breast milk. ${ }^{12,13}$ In this study, we assess the association between breastfeeding and the development of allergic disease in infants 1 year of age, avoiding reverse causation with a risk period-specific analysis.

\section{METHODS}

\section{Study Subjects}

The KOALA (Child, Parent and Health: Lifestyle and Genetic Constitution [in Dutch]) Birth Cohort Study is a prospective birth cohort study in the Netherlands. The design, inclusion criteria, and exclusion criteria have been described in detail elsewhere. ${ }^{14}$ Briefly, from October 2000 to December 2002, we recruited participants with diverse lifestyles (conventional and alternative). Pregnant women with a conventional lifestyle $(n=$ 2343) were recruited from an ongoing prospective cohort study on pregnancy-related pelvic girdle pain (PPGP) in the Netherlands. ${ }^{15}$ Enrollment of pregnant women aimed at 14 to 16 weeks of gestation. At 34 weeks of gestation, PPGP subjects were asked to participate in the KOALA study. In addition, pregnant women with an alternative lifestyle $(n=491)$ were recruited through several "alternative" channels, including organic food shops, anthroposophic doctors and midwifes, Steiner Schools, and magazines. The KOALA study was approved by the ethics committee of the University Hospital Maastricht, and all parents provided informed consent for the study.

\section{Data Collection}

During pregnancy and during the first 2 years after delivery, information on breastfeeding, other determinants, and allergic outcomes were collected for all members of the cohort, with repeated questionnaires at 34 weeks of gestation and at 3, 7, 12, and 24 months. On the date of analysis, the 12-month follow-up assessment was completed. In the present study, the presence of all questionnaires at 3 months, 7 months, and 1 year after delivery was used as a criterion for selecting participants for analysis of the relationships of interest.

\section{Definitions of Exposures}

Breastfeeding was categorized (according to the timing of our questionnaires) as follows. The category "never" served as the reference category and consisted of all infants who never received breastfeeding. All breastfed infants were categorized into the following categories, according to the age at which any breastfeeding ceased: before 4 months of age, 4 to 6 months, or $\geq 7$ months.

\section{Outcome Measurements}

Information on the development of eczema (based on International Study of Asthma and Allergies in Childhood questions) was obtained in the 3-month, 7-month, and 12-month questionnaires. For the overall analysis, we defined eczema in the first year on the basis of the 7-month and 12-month questionnaires. Parents were asked, "Has your child ever had an itchy rash that was coming and going in the past months?" If this question was answered affirmatively, then infants were defined as having developed eczema in the first year of life. Cases of only diaper rash, rash around the eyes, and/or scalp scaling were excluded. For the risk period-specific analyses, we distinguished 2 risk periods, namely, 0 to 3 months (cases of eczema that started in the first 3 months, including cases that did not persist after 3 months) and $\geq 4$ months (cases of eczema that started after 3 months of age).

\section{Definitions of Confounders}

Adjustments were made for the following potential confounders: age at first introduction of solids, defined in periods (after age of 4 months, after age of 5 months, after age of 6 months, or after age of 7 months) in which the infant received any solid food (eg, dairy products, porridge, or fruit mash) for the first time; gender of infant; recruitment group (conventional cohort or alternative cohort); maternal smoking during pregnancy (yes or no); infant's exposure to environmental tobacco smoke (yes or no); maternal age at delivery (in years); maternal education (primary school, preparatory vocational, or lower general secondary education [low], vocational, higher general secondary, or preuniversity education [middle], or higher vocational or academic education [high]); presence of parental allergic disease (ie, self-reported eczema, hay fever, house dust mite allergy, food allergy, and/or asthma) (both parents nonallergic, only father allergic, only mother allergic, or both parents allergic); number of siblings (no siblings, 1 sibling, or $\geq 2$ siblings); and presence of older allergic 
siblings (no siblings, older allergic sibling, or older nonallergic sibling).

\section{Statistical Methods}

Relationships were analyzed by using logistic regression analysis. Results are presented as odds ratios (ORs) with corresponding 95\% confidence intervals (CIs) and were adjusted for potential confounders, which were placed in the logistic regression model simultaneously. Effect modification by recruitment group (conventional or alternative), presence of an allergic parent, or presence of an allergic sibling was assessed by using the likelihood ratio test, comparing models with and without interaction terms. To avoid an influence of disease onset on exposure (reverse causation), we performed risk period-specific analyses, considering exposure only before the risk period.

\section{RESULTS}

Of the 2834 infants enrolled at birth, 2405 parents had completed the 3 questionnaires at infant's age of 1 year ( 3 months, 7 months, and 12 months after delivery); that is, $1941(83 \%)$ of 2343 participants in the conventional cohort and $464(95 \%)$ of 491 participants in the alternative cohort were eventually included in our analyses. The participation rate of KOALA participants recruited from the PPGP study was $39 \%$. The response rates for the 3-month, 7-month, and 12 -month questionnaires were $94 \%, 92 \%$, and $90 \%$, respectively.

Table 1 shows the baseline characteristics of the 2 recruitment groups combined. We noted several differences between the cohorts; mothers in the alternative cohort had a higher rate and longer duration of breastfeeding, compared with the conventional cohort $(\geq 7$ months: $71 \%$ and $28 \%$, respectively). Also, they showed greater delay in the age of first introduction of solid foods (>7 months: $39 \%$ and $21 \%$, respectively). Other characteristics that differed between the alternative cohort and the conventional cohort were maternal smoking during pregnancy (yes: $<1 \%$ and $8 \%$, respectively), exposure to environmental tobacco smoke (yes: $<1 \%$ and $4 \%$, respectively), maternal age (mean: 34 years and 32 years, respectively), maternal education (high education: $73 \%$ and $43 \%$, respectively), and number of siblings ( $\geq 2$ siblings: $21 \%$ and $13 \%$, respectively). In all analyses, we considered recruitment group as a potential effect modifier for the relationship between breastfeeding and eczema. However, we found no significant interaction between recruitment group and breastfeeding in the logistic regression models (always $P>.5$ for interaction). Therefore, we present all results for the groups combined. Also, no interaction between breastfeeding and the presence of an allergic parent or an older allergic sibling was found $(P>.28)$.

The results of the overall analysis are presented in Table 2 . The results showed a tendency toward a lower
TABLE 1 Baseline Characteristics $(N=2405)$

\begin{tabular}{lc}
\hline Breastfeeding, $n$ (\%) & \\
Never & $358(15)$ \\
$0-3$ mo & $745(31)$ \\
$4-6$ mo & $430(18)$ \\
$\geq 7$ mo & $872(36)$ \\
Age at introduction of solid foods, mean \pm SD, mo & $3 \pm 1$ \\
Male gender of infant, $n$ (\%) & $1231(51)$ \\
Maternal smoking during pregnancy (34 wk), $n$ (\%) & $150(6)$ \\
Infant exposed to ETS at age 1 $y, n$ (\%) & $88(4)$ \\
Maternal age at time of delivery, mean \pm SD, $y$ & $32 \pm 4$ \\
Maternal education, $n$ (\%) & \\
Low & $222(9)$ \\
Middle & $1009(42)$ \\
High & $1174(49)$ \\
Parental allergic disease, $n$ (\%) & \\
Both parents nonallergic & $1165(48)$ \\
Only father allergic & $460(19)$ \\
Only mother allergic & $510(21)$ \\
Both parents allergic & $270(11)$ \\
No. of siblings, $n$ (\%) & \\
0 & $1058(44)$ \\
1 & $966(40)$ \\
$\geq 2$ & $358(15)$ \\
Presence of older allergic siblings, $n$ (\%) & \\
No siblings & $1058(44)$ \\
Older nonallergic sibling(s) & $947(39)$ \\
Older allergic sibling(s) & $377(16)$ \\
\hline Values may not add up to the total number because of missing values. ETS indicates environ- \\
mental tobacco smoke.
\end{tabular}

TABLE 2 Overall Analysis of Breastfeeding and Incidence of Eczema in the First 1 Year of Life

\begin{tabular}{crrll}
\hline Breastfeeding & Total No. & No. (\%) & \multicolumn{2}{c}{ Eczema in First 1 y of Life } \\
\cline { 3 - 5 } & & & OR $^{\mathrm{a}}(95 \% \mathrm{Cl})$ & $\begin{array}{c}\text { Adjusted OR } \\
(95 \% \mathrm{Cl})\end{array}$ \\
\hline Never & 358 & $79(22)$ & 1.0 (reference) & 1.0 (reference) \\
0-3 mo & 745 & $168(23)$ & $1.02(0.76-1.39)$ & $0.98(0.71-1.34)$ \\
$4-6$ mo & 430 & $100(23)$ & $1.07(0.77-1.50)$ & $0.94(0.66-1.34)$ \\
$\geq 7$ mo & 872 & $188(22)$ & $0.97(0.72-1.31)$ & $0.80(0.57-1.12)$ \\
Total & 2405 & $535(22)$ & & \\
\hline
\end{tabular}

All infants were included in the analysis.

a $P=.76$ for trend.

${ }^{b}$ Adjusted for age at introduction of solid foods, gender, recruitment group, maternal smoking during pregnancy, infant's exposure to environmental tobacco smoke, maternal age, maternal education, parental allergic disease, number of siblings, and presence of older allergic siblings $(P=.13$ for trend $)$

risk of eczema in the first year of life associated with breastfeeding, but this was not statistically significant. For the risk period of $\geq 4$ months, we considered only eczema cases with onset after 3 months, and we combined the exposure categories of 4 to 6 months and $\geq 7$ months into 1 category of $\geq 4$ months to avoid reverse causation. The results again showed a tendency toward a lower risk of eczema developing between 4 and 12 months of life associated with breastfeeding, which was not statistically significant (Table 3 ).

The effect of starting breastfeeding on early development of eczema $(0-3$ months; $n=514)$ was analyzed 


\begin{tabular}{|c|c|c|c|c|}
\hline TABLE 3 & \multicolumn{4}{|c|}{$\begin{array}{l}\text { Period-Specific ( } \geq 4 \text { Months) Analysis of Breastfeeding } \\
\text { and Incidence of Eczema Between } 4 \text { and } 12 \text { Months }\end{array}$} \\
\hline \multirow[t]{2}{*}{ Breastfeeding } & \multirow[t]{2}{*}{ Total No. } & \multirow[t]{2}{*}{ No. (\%) } & \multicolumn{2}{|c|}{ Eczema Between 4 and 12 mo } \\
\hline & & & $\mathrm{OR}^{\mathrm{a}}(95 \% \mathrm{Cl})$ & $\begin{array}{l}\text { Adjusted ORb } \\
(95 \% \mathrm{Cl})\end{array}$ \\
\hline Never & 578 & $79(14)$ & 1.0 (reference) & 1.0 (reference) \\
\hline $0-3 \mathrm{mo}$ & 1019 & $126(12)$ & $1.00(0.68-1.46)$ & $0.98(0.66-1.46)$ \\
\hline$\geq 4 \mathrm{mo}$ & 578 & $79(14)$ & $0.84(0.59-1.20)$ & $0.77(0.52-1.15)$ \\
\hline Total & 1891 & $246(13)$ & & \\
\hline
\end{tabular}

The incidence of eczema in the risk period of 4 to 12 months was analyzed (ie, excluding infants with onset of eczema before 3 months of age).

a $P=22$ for trend.

b Adjusted for age at introduction of solid foods, gender, recruitment group, maternal smoking during pregnancy, infant's exposure to environmental tobacco smoke, maternal age, maternal education, parental allergic disease, number of siblings, and presence of older allergic siblings $(P=.14$ for trend).

subsequently, among infants who were excluded in the risk period ( $\geq 4$ months)-specific analysis mentioned above. A slightly higher risk of early eczema was found for infants who were breastfed from birth on (ever breastfed), compared with infants who were formula fed from birth on (never breastfed), but this was not statistically significant (early eczema in ever-breastfed group: 450 of 2047 infants, $22.0 \%$; never-breastfed group: 64 of 358 infants, 17.9\%; adjusted OR: 1.30; 95\% CI: 0.961.77). Notably, the risk of infants whose mothers attempted breastfeeding but could not establish it (breastfeeding of $<4$ weeks; $22 \%$ with eczema) was not essentially different from that of infants who managed breastfeeding for $>4$ weeks but ceased before 4 months of age ( $23 \%$ with eczema).

\section{DISCUSSION}

In the present study, we found no association between breastfeeding and the development of eczema in the first year of life. We found a tendency toward a lower risk of eczema that started at $\geq 4$ months of age and a tendency for a higher risk of early eczema, but both were not statistically significant. When we compared the overall analysis and the risk period ( $\geq 4$ months)-specific analysis, the results were not very different. Therefore, we conclude that there was no substantial reverse causation. An advantage of our study is the relatively short time intervals between subsequent follow-up questionnaires, which makes the influence of recall bias less likely. Follow-up rates were high, which limits the possibility of differential bias regarding baseline characteristics or outcomes. However, families with allergic complaints tend to be over-represented in studies on causes of atopy. The difference between participants and nonparticipants may be explained by self-selection, because people with a positive family history of allergic disease tend to be more interested in participating in studies on health-related topics. Also, participants in the KOALA study had more intention to breastfeed than did nonparticipants. ${ }^{14}$ However, relative risk associations are not biased, in our opinion, because relative risks are based on proportions and not absolute numbers.

Two other studies also found no relationship between breastfeeding and eczema. ${ }^{16,17}$ Other observational studies and a meta-analysis found a protective association between duration of breastfeeding and eczema. .,18-23 $^{8}$ Some studies even found breastfeeding to be a risk factor for the development of eczema., ${ }^{3,46}$ For example, Bergmann et $\mathrm{al}^{4}$ showed that the prevalence of atopic eczema in the first 7 years increased by $3 \%$ with each additional 1 month of breastfeeding. However, those authors suggested that the possibility that their results were influenced by reverse causation could not be ruled out. The idea that early atopic symptoms influence the duration of breastfeeding was demonstrated recently by Lowe et al. ${ }^{24}$ Reverse causation could be an explanation for the inconsistent results between different studies., ${ }^{4-9}$ Also, reverse causation may be more likely to be evident in the relationship between exclusive breastfeeding and risk of developing eczema. Recently, Zutavern et $\mathrm{al}^{9}$ suggested that reverse causation is a relatively new problem because, in older studies, public awareness of the healthpromoting effects of breastfeeding was smaller.

Two solutions have been proposed in the literature to avoid reverse causation. First, survival analysis (Cox regression analysis) is a suitable method to consider only breastfeeding before the appearance of eczema. ${ }^{17}$ However, survival analysis requires data on the exact onset of eczema in small time intervals, which many studies lack. Second, reverse causation can be avoided by excluding infants with onset of disease during lactation. ${ }^{7,9,25}$ This is equivalent to a risk period-specific analysis confined to infants at risk (avoiding overlap between exposure and disease outcome). Such an analysis has the additional advantage that it keeps track of infants with early symptoms (such as the infants with early eczema in our study).

In the present study, the results of such a risk periodspecific analysis were not substantially different, compared with the results of the overall analysis. In our opinion, we have demonstrated that our main finding (breastfeeding does not influence the risk of eczema in the first year of life) is unlikely to be biased by reverse causation. In addition, we examined more specifically all infants with reported eczema in the first 3 months (ie, infants with early symptoms who were excluded in the risk period-specific analysis). Infants who were ever breastfed had a slightly (although not statistically significantly) increased risk of eczema at the age of 3 months, compared with completely (from birth) formula-fed infants. With regard to this finding, our analysis did not address both the duration of breastfeeding and the onset of eczema. To avoid reverse causation, the discrimination between starting breastfeeding versus formula feeding from birth is the only useful comparison. That is, no overlap occurs between exposure immediately after 
birth and onset of disease; because the disease is not yet present immediately after birth, the choice of the feeding regimen immediately after birth cannot be biased by disease.

\section{CONCLUSIONS}

We found no strong evidence for a protective effect of breastfeeding on eczema in the first year of life. We think that our results were strengthened by avoiding reverse causation as a potential bias. Controlling for reverse causation can be accomplished by risk period-specific analyses in which only exposure before the risk period is taken into account. Our findings do not necessarily mean that reverse causation will be absent in other study populations in which the presumed protective effect of breastfeeding is more widely advocated. Therefore, in studies addressing the controversial relationship between breastfeeding duration and the development of allergic diseases, exploring reverse causation is a prerequisite for retrieving results with a minimal chance of bias.

\section{ACKNOWLEDGMENTS}

This study was supported financially by the Netherlands Organisation for Health Research and Development Program of Innovative Prevention Research (Prevention Program 1, grant 210-00-090).

We thank Frans Tan and Monique Mommers for their useful comments.

\section{REFERENCES}

1. Kramer MS. Does breast feeding help protect against atopic disease? Biology, methodology, and a golden jubilee of controversy. J Pediatr. 1988;112:181-190

2. Saarinen UM, Kajosaari M. Breastfeeding as prophylaxis against atopic disease: prospective follow-up study until 17 years old. Lancet. 1995;346:1065-1069

3. Wetzig H, Schulz R, Diez U, et al. Associations between duration of breast-feeding, sensitization to hens' eggs and eczema infantum in one and two year old children at high risk of atopy. Int $J$ Hyg Environ Health. 2000;203:17-21

4. Bergmann RL, Diepgen TL, Kuss O, et al. Breastfeeding duration is a risk factor for atopic eczema. Clin Exp Allergy. 2002; 32:205-209

5. Sears MR, Greene JM, Willan AR, et al. Long-term relation between breastfeeding and development of atopy and asthma in children and young adults: a longitudinal study. Lancet. 2002;360:901-907

6. Purvis DJ, Thompson JM, Clark PM, et al. Risk factors for atopic dermatitis in New Zealand children at 3.5 years of age. Br J Dermatol. 2005;152:742-749

7. Kull I, Almqvist C, Lilja G, et al. Breast-feeding reduces the risk of asthma during the first 4 years of life. J Allergy Clin Immunol. 2004; 114:755-760

8. Laubereau B, Brockow I, Zirngibl A, et al. Effect of breastfeeding on the development of atopic dermatitis during the first 3 years of life: results from the GINI-birth cohort study. $J \mathrm{Pe}$ diatr. 2004; 144:602-607

9. Zutavern A, Brockow I, Schaaf B, et al. Timing of solid food introduction in relation to atopic dermatitis and atopic sensitization: results from a prospective birth cohort study. Pediatrics. 2006;117:401-411

10. Wright AL, Holberg CJ, Taussig LM, et al. Factors influencing the relation of infant feeding to asthma and recurrent wheeze in childhood. Thorax. 2001;56:192-197

11. Horwitz RI, Feinstein AR. The problem of "protopathic bias" in case-control studies. Am J Med. 1980;68:255-258

12. Isolauri E, Tahvanainen A, Peltola T, et al. Breast-feeding of allergic infants. J Pediatr. 1999;134:27-32

13. Jarvinen KM, Suomalainen H. Development of cow's milk allergy in breast-fed infants. Clin Exp Allergy. 2001;31:978-987

14. Kummeling I, Thijs C, Penders J, et al. Etiology of atopy in infancy: the KOALA Birth Cohort Study. Pediatr Allergy Immunol. 2005; 16:679-684

15. Bastiaanssen JM, de Bie RA, Bastiaenen $\mathrm{CH}$, et al. Etiology and prognosis of pregnancy-related pelvic girdle pain: design of a longitudinal study. BMC Public Health. 2005;5:1.

16. Ludvigsson JF, Mostrom M, Ludvigsson J, et al. Exclusive breastfeeding and risk of atopic dermatitis in some 8300 infants. Pediatr Allergy Immunol. 2005; 16:201-208

17. Benn CS, Michaelsen KF. Does the effect of breast-feeding on atopic dermatitis depend on family history of allergy? J Pediatr. 2005; 147:128-129

18. Kull I, Wickman M, Lilja G, et al. Breast feeding and allergic diseases in infants: a prospective birth cohort study. Arch Dis Child. 2002;87:478-48

19. Kull I, Bohme M, Wahlgren CF, et al. Breast-feeding reduces the risk for childhood eczema. J Allergy Clin Immunol. 2005; 116:657-661

20. van Odijk J, Kull I, Borres MP, et al. Breastfeeding and allergic disease: a multidisciplinary review of the literature (1966-2001) on the mode of early feeding in infancy and its impact on later atopic manifestations. Allergy. 2003;58: 833-843

21. Gdalevich M, Mimouni D, David M, et al. Breast-feeding and the onset of atopic dermatitis in childhood: a systematic review and meta-analysis of prospective studies. J Am Acad Dermatol. 2001:45:520-527

22. Kerkhof M, Koopman LP, van Strien RT, et al. Risk factors for atopic dermatitis in infants at high risk of allergy: the PIAMA study. Clin Exp Allergy. 2003;33:1336-1341

23. Schoetzau A, Filipiak-Pittroff B, Franke K, et al. Effect of exclusive breast-feeding and early solid food avoidance on the incidence of atopic dermatitis in high-risk infants at 1 year of age. Pediatr Allergy Immunol. 2002;13:234-242

24. Lowe AJ, Carlin JB, Bennett CM, et al. Atopic disease and breast-feeding: cause or consequence? J Allergy Clin Immunol. 2006; 1 17:682-687

25. Wickman M, Kull I, Pershagen G, et al. The BAMSE project: presentation of a prospective longitudinal birth cohort study. Pediatr Allergy Immunol. 2002;13(suppl 15):11-13 


\section{Breastfeeding and Infant Eczema in the First Year of Life in the KOALA Birth Cohort Study: A Risk Period-Specific Analysis}

Bianca E. P. Snijders, Carel Thijs, Ischa Kummeling, John Penders and Piet A. van den Brandt

Pediatrics 2007;119; e137-e141

DOI: $10.1542 /$ peds.2006-0772

\section{Updated Information \\ \& Services}

References

Post-Publication

Peer Reviews ( $\left.\mathbf{P}^{3} \mathbf{R s}\right)$

Subspecialty Collections

Permissions \& Licensing

Reprints including high-resolution figures, can be found at: http://www.pediatrics.org/cgi/content/full/119/1/e137

This article cites 24 articles, 3 of which you can access for free at:

http://www.pediatrics.org/cgi/content/full/119/1/e137\#BIBL

One $\mathrm{P}^{3} \mathrm{R}$ has been posted to this article:

http://www.pediatrics.org/cgi/eletters/119/1/e137

This article, along with others on similar topics, appears in the following collection(s):

Allergy \& Dermatology

http://www.pediatrics.org/cgi/collection/allergy_and_dermatolog y

Information about reproducing this article in parts (figures, tables) or in its entirety can be found online at: http://www.pediatrics.org/misc/Permissions.shtml

Information about ordering reprints can be found online: http://www.pediatrics.org/misc/reprints.shtml

\section{American Academy of Pediatrics}

